permanent agriculture could easily be cited.

All long-continued investigations and, likewise, all practical agricultural experience show that great reduction in crop yields ultimately occurs unless plant food is restored to the soil; and, as a rule, the chemical composition of normal soil is an exceedingly valuable guide in determining the kinds of material which should be supplied in practical systems of soil enrichment and preservation.

UNIVERSITY OF ILLINOIS

$$
\text { CyrIL G. Hopkins }
$$

\section{THE FIFTH INTERNATIONAL CONGRESS OF MATHEMATICIANS}

ONCE every four years the mathematicians of the world meet together to discuss the new discoveries made in the various branches of their science, to review the work accomplished during the past quadrennial period, to listen to mathematical papers and to become acquainted with one another. The fifth International Congress of Mathematicians was held at Cambridge University, August 21 to 28, 1912, at the invitation of the Cambridge Philosophical Society. The four former congresses were Zurich, 1897 ; Paris, 1900 ; Heidelberg, 1904; Rome, 1908. During the World's Fair at Chicago in 1893, a similar international gathering of mathematicians was held, but this meeting is not usually included in the list of meetings of the International Congress.

The opening meeting was devoted to welcoming addresses by the president of the Cambridge Philosophical Society, Sir George Darwin, and the vice-chancellor of the university, Mr. R. F. Scott. Sir George Darwin emphasized the great trend towards specialization among modern mathematicians and referred to the great loss sustained by mathematics in the recent death of Henri Poincarê, who was probably the one man competent to appreciate mathematical research in all its diverse branches. Darwin referred to the Cambridge School of Applied Mathematicians in the last century, mentioning Airy, Adams, Maxwell, Stokes, Kelvin and Rayleigh, and analyzed the characteristic differences in the mental attitudes of the pure and applied mathematician.

The officers of the congress were elected as follows: President, Sir George Darwin; Vicepresidents, W. von Dyck, L. Fejér, R. Fujisawa, J. Hadamard, J. L. W. V. Jensen, P. A. Mac.Mahon, G. Mitlag-Leffler, E. H. Moore, F. Rudio, P. H. Schoute, M. S. Smoluchowski, V. A. Steklov, V. Volterra; General Secretaries, E. W. Hobson and A. E. H. Love.

The congress was organized in four sections devoted, respectively, to arithmetic-algebraanalysis, geometry, applied mathematics and philosophical, historical and didactical questions. The section of applied mathematics was divided into two, one for mathematical physics and astronomy, the other for economics and statistics. This was done also in the case of the fourth section, one section taking up philosophy and history, the other didactics. The international committee having charge of the program appointed the first chairmen of the sections, each of whom gave a short introductory address. The other chairmen were appointed by the sections from day to day.

Section I. Arithmetic, Algebra, Analysis.The first meeting was presided over by Professor E. B. Elliott, who in his opening address defended the British mathematician from the attacks of those who have said he is too self-centered and cared little for the furtherance of mathematical thought. In the five meetings of this section 28 papers were offered and open for discussion. Many of the papers dealt with that part of the field of analysis which centers about the integral equation. The chairmen for the meetings after the first were Professors E. Landau, E. Borel, E. H. Moore, H. von Koch.

Section II. Geometry.-The chairman of the first meeting, Dr. H. P. Baker, gave a brief survey of the present state of the theory of surfaces and extensions to space of more than three dimensions, and gave reasons for his belief that geometers were now on the threshold of many new discoveries through the 
mingling of the two streams of investigations associated with the name of the French mathematician Picard and with the modern Italian school. Twenty-four papers were read. The chairmen of the later meetings were Professors F. Severi, F. Morley, J. Drach.

Section IIIa. Mathematical Physics.Chairman Professor H. Lamb commented upon the division of applied mathematicians into three classes, those whose interests lay mainly in the pure mathematical aspect of the problems of experience, those to whom analysis was only a means towards the interpretation and coordination of phenomena, and those specially represented in the Cambridge school who found a sort of esthetic interest in the reciprocal interplay of experience and theory. Twenty-seven papers were read in this meeting and those presided over by Prince Galatzin and Professors. T. Levi-Civita and P. Stäckel.

Section IIIb. Economics, Statistics and Actuarial Science.-Professor. F. Y. Edgeworth, presiding at the first meeting, commented on the fact that for the first time this branch of applied mathematics had been given equal rank with the older branches and referred to the pioneering work of Marshall as a mathematical economist and to the importance of the calculus of probabilities in the development of actuarial science. Dr. M. F. Sheppard and Dr. J. F. Steffensen presided at the two last meetings. A total of 13 papers made up the program of the three meetings.

Section IVa. Philosophy and HistoryFour meetings of this section were held, one a joint meeting with Section IVb. Twentytwo papers were offered. The meetings were presided over by Hon. B. A. W. Russell, Professors A. Gutzmer, A. Padoa, F. Rudio.

Section IVb. Didactics.-The first chairman, Mr. C. Godfrey, spoke regretfully of the absence of Klein, who had done so much in promoting the work of the International Commission on the Teaching of Mathematics. The chairman happily characterized the section as devoted to the study of functions of two variables, one being mathematics, the other the student. Three of the five meetings of this section were occupied with the presentation of reports from the various countries to the International Commission. Over 150 reports have been published and 50 more are in preparation. Professors C. Bourlet, J. W. A. Young, E. Czuber, D. E. Smith, R. Fujisawa, were chairmen of the meetings at which ten papers were read. At a special meeting of this section presided over by Sir J. J. Thomson, Professor Runge read a paper on the mathematical education of the physicist which brought forth an animated discussion. Runge's report was made up from the answers received to inquiries sent to universities in many countries, which summed up that need was felt for mathematicians and physicists to draw closer together, more attention should be given to graphical and approximate methods and to numerical computation by mathematical teachers and that instruction in mathematics should be individual. Several speakers in discussing the paper deplored the widening gap between the pure mathematician and the physicist, but it was suggested that the gap should be closed not by compelling mathematical teachers to abandon logical precision, but by discarding things obsolete in the traditional mathematical courses and diminishing the excessive amount of manipulative work which is now demanded from physics students.

Besides the sectional meetings there were ten lectures given at the general meetings of the congress. These lectures were:

" II significato della critica dei principii nello' sviluppo delle matematiche," Professor F. Enriques.

"Periodicity in the solar system," Professor E. W. Brown.

6. The history and evolution of arithmetic division," P. J. Harding.

"The principles of instrumental seismology,", Prince B. Galitzin.

"Gelöste und ungelöste Probleme aus der Theorie der Primzahlverteilung und der Riemannschen Zetafunktion,', Professor E. Landau.

"Definition et domaine d'existence des fonctions monogénes uniformes,', Professor E. Borel.

"The place of mathematics in engineering practise," Sir W. H. White.

"Multiply charged atoms;"' Sir J. J. Thomson. 
"'Boundary problems in one dimension," Professor M. Bôcher.

"The dynamics of radiation," Sir J. Larmor.

The lecture by Sir W. H. White will no doubt cause a discussion with followers of Professor John Perry for the speaker preferred "pure mathematics taught by a mathematician to the so-called practical mathematics."

From a social standpoint the members were well taken care of. On Wednesday evening, August 21, they were received in the Combination Room and Hall of St. John's College by Sir George Darwin as president of the Cambridge Philosophical Society, and Mr. R. F. Scott, vice-chancellor of the university. On Friday evening they attended a reception at Fitzwilliam Museum given by Lord Rayleigh, the chancellor of the university. Sunday afternoon was given up to a reception by the committee on organization in the gardens of Christ's College. An organ recital was given in King's College chapel on Sunday night. On Monday night the master and fellows of Trinity College received the members in the college. One afternoon was devoted to an excursion to Ely and its cathedral. An excursion to Oxford was arranged for the day after the breaking up of the congress. On this day many accepted the invitation of the Marquis of Salisbury to visit Hatfield House. Facilities were given for visits to the works of the Cambridge Scientific Instrument Making Company, the visitors being entertained by Mrs. Horace Darwin. Visitors to the university observatory were entertained by Mrs. Newall. Besides these, there were many little gatherings and excursions for the ladies who did not care to attend the mathematical meetings. The feature of this congress was the hospitality of the Cambridge colleges. A majority of the members of the congress lived in the colleges and for those of us who were so fortunate, this part of the week's entertainment was one we shall long remember.

On Tuesday a procession was formed and a wreath of laurel and white flowers was carried to and placed on the grave of the Cambridge mathematician, Arthur Cayley, in Millroad Cemetery. Professor S. Dickstein, of
Warsaw, delivered an appreciation of Cayley's work. From the money left over from the subscription for the wreath a memorial of the occasion is to be made in silver and presented to the university.

The congress was well attended, the total number of members registering being 706 from 27 countries. This is somewhat larger than the attendance at Rome in 1904 and much larger than at any other congress. About 85 Americans were present. With the exception of the United Kingdom the United States was represented by the largest number of members, Germany and France coming next in order. At the last meeting the invitation of Professor Mittag-Leffler to hold the next meeting at Stockholm in 1916 was accepted. Invitations to hold the 1920 meeting in Budapesth and in Athens were received, but no action was taken.

\section{A. R. Crathorne}

\section{THE NEW ENGLAND GEOLOGICAL EXCURSION}

The twelfth annual Geological Excursion of the New England colleges and universities was held in the vicinity of Meriden, Connecticut, October 18 and 19, under the direction of Professor William North Rice, of Wesleyan University, and was attended by representatives from Amherst, Connecticut Agricultural College, Harvard, Mount Holyoke, Massachusetts Agricultural College, Massachusetts Institute of Technology, Smith, Trinity, Tufts, University of Vermont, Wesleyan, Williams, and Yale, teachers of geography from a number of the high schools of Connecticut, about fifty men and women participating.

After a collation at Fisk Hall in Middletown, given by Wesleyan University, the party listened to an illustrated lecture by Professor Barrell, of Yale University, on "Central Connecticut in the Geologic Past" and a brief statement by Professor Rice on the localities to be studied on the following day. After the meeting the party went to Meriden by trolley, where they spent the night. On Saturday morning the party went by special car on the 